*ak FMIS View/Frint Document Cover Sheet tow

This document was retrieved from the Documentation and Records Management (DRM) ISEARCH System. It is intended for Information only and may not be the most recent or updated version. Contact a Document Service Center (see Hanford Info for locations) if you need additional retrieval information.

Accession \#: D196077714

Document \#: SD-WM-TA-175

Title/Desc:

TECHNICAL BASIS FOR IMPLEMENTING THE USE OF THE PCM-1B FOR PERSONNEL RELEASES AT TANK FARMS [DIRECT REV]

Pages: 17 


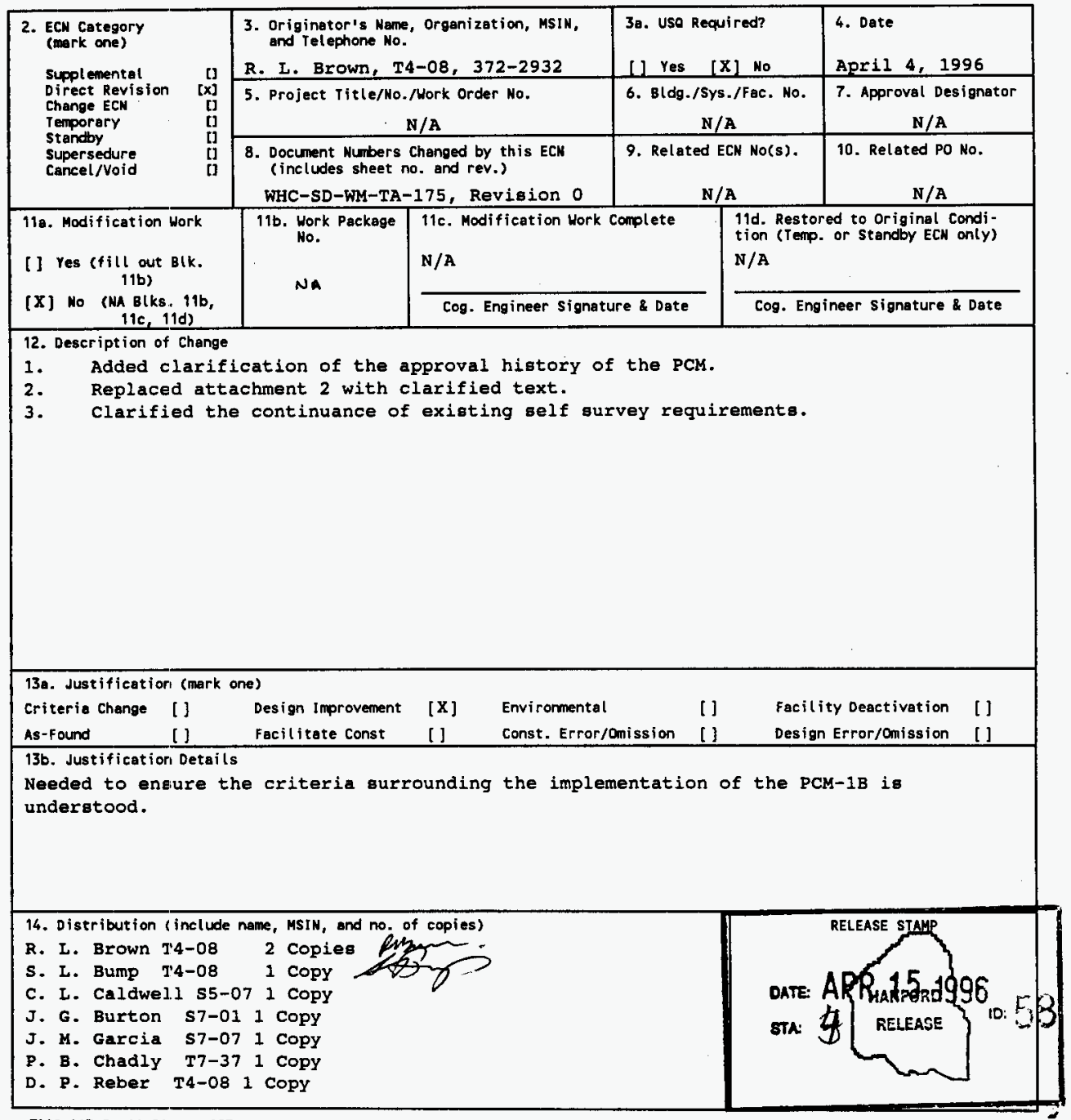




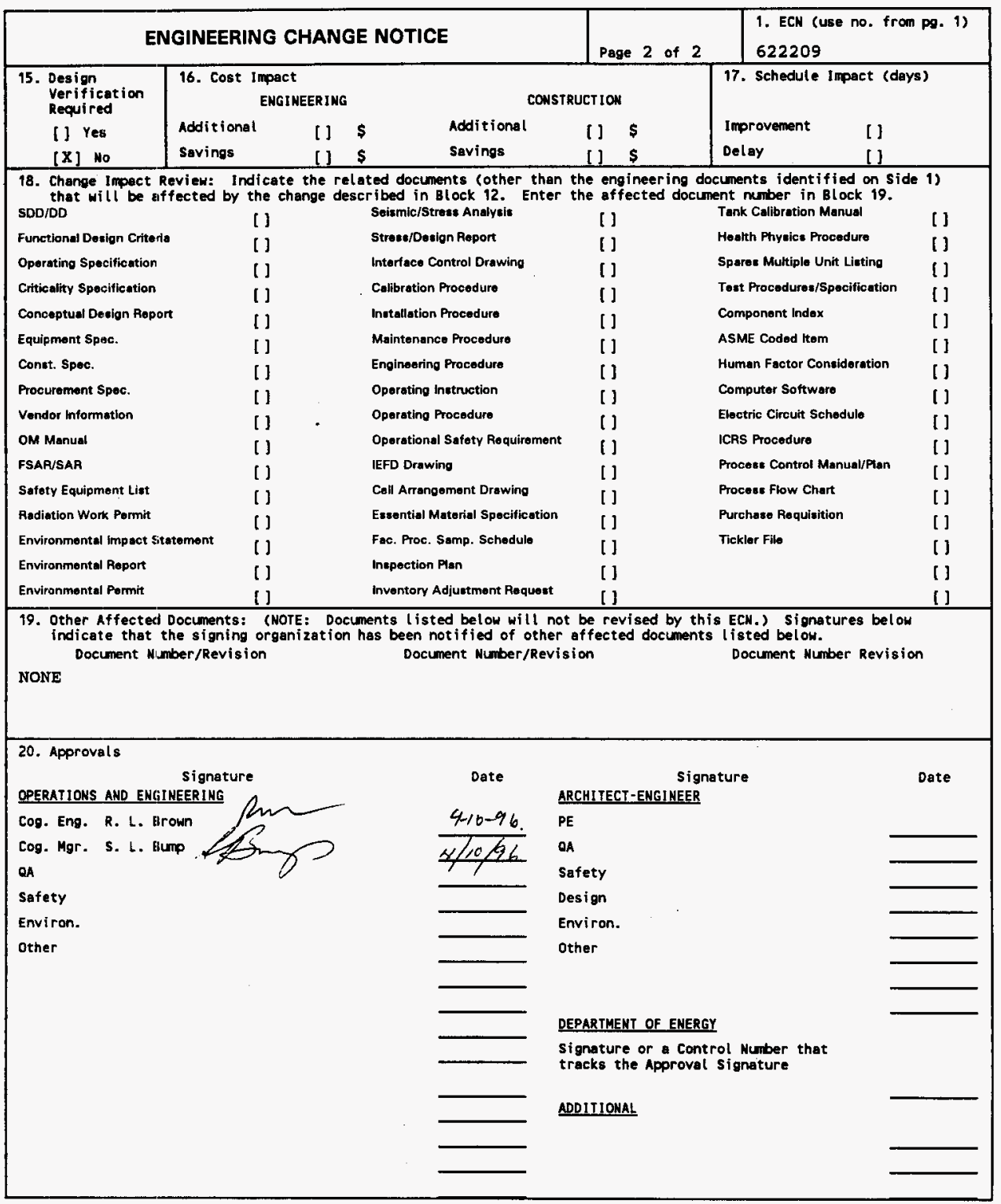




\title{
Technical Basis For Implementing The Use Of The PCM-1B For Personnel Releases At Tank Farms
}

\author{
R. L. Brown \\ Westinghouse Hanford Company \\ Richland, WA 99352 \\ U.S. Department of Energy Contract DE-AC06-87RL10930 \\ $\begin{array}{lll}\text { EIDT/ECN : } & \text { ECN-622209 } & \text { UC: } 2080 \\ \text { Org Code: } & 333 A 0 & \text { Charge Code: N1873 } \\ \text { BixR Code: } & \text { NA } & \text { Total Pages: } \$\end{array}$ \\ Key worde: PCM, FRISKING, GM, PANCAKE PROBE, SURVEY, SELF-SURVEYS \\ Abstract: This document describes implementation process for applying \\ PCM-B instruments to perform personnel release surveys.
}

TRADEMARK OISCLAIMER. Reference herein to any specific comercial product, process, or service by trade name, trademark, menufacturer, or otherwise, does not necessarily constitute or imply its endorsement, recommendation, or favoring by the United States Government or any agency thereof or its contractors or subcontractors.

Printed in the United states of America. To obtain copies of this document, contact: WHC/BCS

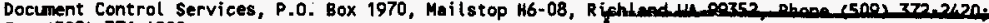
Fax (509) 376-4989.
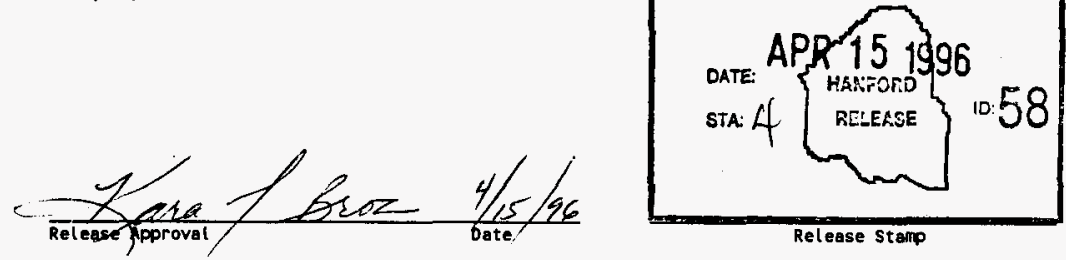

Release Stamp 


\section{RECORD OF REVISION}

(2) Title

Technical Bagia for Implementing the Use of the PCM-1B at Tank Farma CHANGE CONTROL RECORD

\begin{tabular}{|l|l|l|l|l|}
\hline \multirow{2}{*}{ (3) Revision } & \multirow{2}{*}{ (4) Description of Change - Replace, Add, and Delete Pages } & \multicolumn{2}{|c|}{ Authorized for Release } \\
\cline { 3 - 5 } & (7) & (5) Cog. Engr. & (6) Cog. Mgr. Date \\
\hline RS 1 & EDT 612902 Igsued March 18, 1996 & \\
\hline
\end{tabular}


WHC-SD-WM-TA-175, Rev. 1

TECHNICAL BASIS FOR IMPLEMENTING THE

USE OF THE PCM-1B FOR PERSONNEL RELEASE AT

AT TANK FARMS

Tank Farms Transition Projects Radiological Control Organization

Westinghouse Hanford Company

R. L. Brown, R. E. Elder, B. C. Gibson, and C. E. Upchurch

Rev. 1 


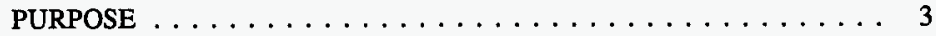

SCOPE $\ldots \ldots \ldots \ldots \ldots \ldots \ldots \ldots \ldots \ldots \ldots \ldots \ldots \ldots \ldots \ldots \ldots$

3.0

SUMMARY AND DISCUSSION $\ldots \ldots \ldots \ldots \ldots \ldots \ldots \ldots$

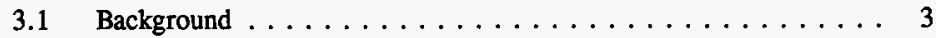

3.2 Summary of Recommendations $\ldots \ldots \ldots \ldots \ldots \ldots \ldots$

3.3 PCM-1B Effectiveness $\ldots \ldots \ldots \ldots \ldots \ldots \ldots \ldots \ldots \ldots$

3.4 Authority Basis $\ldots \ldots \ldots \ldots \ldots \ldots \ldots \ldots \ldots$

4.0

ASSESSMENTS OF CRITERIA, STANDARDS AND

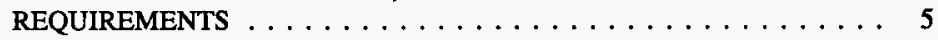

4.1 Applicable Standards . . . . . . . . . . . . . 5

4.2 Explanation of Potential Implementation Issues $\ldots \ldots \ldots \ldots$

IMPLEMENTATION .................. 9

5.1 Communication ................. 9

5.2 Required Actions $\ldots \ldots \ldots \ldots \ldots \ldots \ldots \ldots$

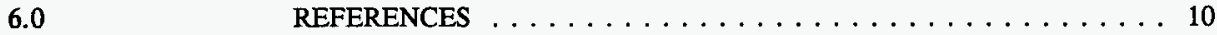

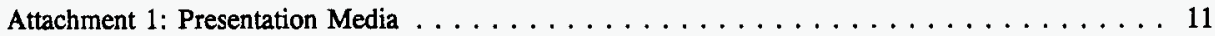

Attachment 2 : Self Survey Instructions $\ldots \ldots \ldots \ldots \ldots \ldots \ldots \ldots \ldots \ldots \ldots \ldots \ldots \ldots \ldots \ldots$ 


\subsection{PURPOSE}

The purpose of this document is to define the required controls for using automated personnel contamination monitors, such as a PCM-1B, at Tank Farm Transition Projects in lieu of a portable instruments for a beta-gamma whole body self survey.

\section{$2.0 \quad$ SCOPE}

This document applies only to Tank Farm Transition Projects. This document does not provide the technical basis for determining the equivalency of an automated system to hand-held instruments, or to the effective counting capability of automated systems as such technical determinations are a matter of record. Reference 3 contains a full discussion of this determination.

\subsection{SUMMARY AND DISCUSSION}

\subsection{Background}

Currently, Tanks Farms Transition Projects require personnel to perform a whole body survey with portable survey instrumentation prior to entering an automated counting system capable of performing a whole body survey. This practice is redundant since automated whole body survey devices are, in most cases, more sensitive and are less likely to be used incorrectly than portable instrumentation. Additionally, Article 221.2 of the Hanford Site Radiological Control Manual (HSRCM-1) states "Monitoring for contamination should be performed using frisking equipment that under laboratory conditions can detect total contamination of at least the values specified in Table 2-2." Based on this criteria implementing the use of an automated whole body survey device would save significant time, money and reduce the current crowding and potential loss of contamination control that now occur during peak times at step off pads.

\subsection{Summary of Recommendations}

The PCM-1B should be used in lieu of a survey using portable instruments where a beta-gamma survey is required.

To implement this effectively, personnel must be informed, self survey training must be modified, and new instructions for surveying at the step off pad must be distributed. Section 4.0 of this document contains discussion of these and other issues.

Where installed and operational, automated survey device use should be mandatory. 


\subsection{PCM-1B Effectiveness}

The PCM-1B has been performance tested and evaluated at numerous DOE sites and commercial power plants yielding similar conclusions. These evaluations demonstrate that the PCM-1B is superior in performance and should be the primary contamination monitor rather than the current use of monitoring stations utilizing pancake-GM survey probes. As a result of one such report, contained in reference 3, the Idaho Falls DOE Field Office authorized the use of the PCM for personnel release on September 13, 1991. This position was adopted, but not implemented, at Westinghouse Hanford Company in 1992, as further discussed in section 3.4.

\subsection{Authority Basis}

Approval for use of the PCM-1B as a personnel release instrument has been documented numerous times. The effort began with a technical basis report written by John Gonsky (Gonsky 88). In the report the effectiveness of a PCM-1 was compared to a hand held frisker under three different configurations, using efficiencies consistent with those associated with Cobalt 60:

Case 1 A single 5000 dpm speck located randomly on the body.

Case $25000 \mathrm{dpm}$ distributed on a $100 \mathrm{~cm}^{2}$ area.

Case $35000 \mathrm{dpm} / 100 \mathrm{~cm}^{2}$ distributed across a large area $\left(>>100 \mathrm{~cm}^{2}\right)$

The following table summarizes the results:

\begin{tabular}{|l|l|l|l|l|l|l||}
\hline & \multicolumn{2}{|l|}{ Case 1 } & \multicolumn{2}{c|}{ Case 2 } & \multicolumn{2}{c|}{ Case 3 } \\
\cline { 2 - 7 } & PCM & $\begin{array}{l}\text { Hand } \\
\text { Frisk }\end{array}$ & PCM & $\begin{array}{l}\text { Hand } \\
\text { Frisk }\end{array}$ & PCM & $\begin{array}{l}\text { Hand } \\
\text { Frisk }\end{array}$ \\
\hline $\begin{array}{l}\text { Probability of } \\
\text { Detection }\end{array}$ & $77 \%$ & $14 \%$ & $77 \%$ & $7 \%$ & $85 \%$ & $59 \%$ \\
\hline $\begin{array}{l}\text { Probability of } \\
\text { False Positive }\end{array}$ & $3 \%$ & $2 \%$ & $3 \%$ & $2 \%$ & $2 \%$ & $5 \%$ \\
\hline
\end{tabular}

The question as to whether a PCM could be used to perform the whole body survey required upon exit from a contamination area was answered in May, 1992. Internal Memo R. E. Heineman to K. R. Jordan, 330000-92-028, Manual Surveys with Portal Monitor Surveys, dated May 19, 1992, was issued stating definitively that the PCM was an authorized alternative to the hand frisk. This memo summarized the industry movement towards automated counting systems, including the decision by the INEL to adopt the PCM as a release instrument. The memo was concurred with by the entire senior staff of the Health Physics organization, including the manager of the 
Radiological Safety, Standards, and Requirements function. A similar memo had been previously written on March 23, 1992 from Bart Gibson, the site cognizant engineer for PSDs, stating the same position; this memo was also concurred with by the manager of Radiological Safety, Standards, and Requirements.

As a follow up, in November of 1993, the Hanford Instrument Evaluation Committee (HIEC) approved the use of the PCM-1B for personnel release applications. This was communicated in a November 1993 Memo, M. L. Johnson to Distribution, Approved Instrument List.

Of all the facilities, only the 222-S Laboratory adopted the use of the PCM as an alternative to hand frisking, a practice still in effect today.

\subsection{ASSESSMENTS OF CRITERIA, STANDARDS AND REQUIREMENTS}

\subsection{Applicable Standards}

4.1.1 Contamination surveys are required upon Contamination Area exit:

HSRCM: Article 221.1 - Personnel exiting Contamination Areas, High Contamination Areas, Airborne Radioactivity Areas or Radiological Buffer Areas established for contamination control shall frisk for contamination as required by Article 338 .

HSRCM: Article 338.1 - Personnel shall perform a whole body frisk under the following conditions: immediately upon exiting Contamination Areas, High Contamination Areas and Airborne Radioactivity Areas; and as directed by the RWP or the Radiological Control Organization.

\subsubsection{Contamination surveys must be performed using appropriate instruments:}

HSRCM: Article 221.2 - Monitoring for contamination should be performed using frisking equipment that under laboratory conditions can detect total contamination of at least the values specified in Table 2-2. Use of automatic monitoring units that meet the above requirements is encouraged. 
4.1.3 Contamination surveys must be performed at the RBA boundary:

HSRCM: Article 338.2 - In addition to the above, personnel exiting a Radiological Buffer Area containing Contamination, High Contamination or Airborne Radioactivity Areas should, at a minimum, perform a hand and foot frisk. This frisk is optional if the Radiological Buffer Area exit is immediately adjacent to the location where the exiting worker has already performed a whole body frisk.

4.1.4 Automated counting devices are preferred over portable instruments:

HSRCM: Article 221.2 (Second Sentence) - "Use of automatic monitoring units that meet the above requirements is encouraged."

HSRCM: Article 338.7 - The use of automated personnel contamination monitors is encouraged.

4.1.5 Personnel must be trained to use the survey instruments:

HSRCM: Article 551.2 - Monitoring shall only be performed by trained and qualified personnel using instruments that are properly calibrated and routinely tested for operability.

\subsection{Explanation of Potential Implementation Issues}

The wording of the above noted requirements is clear as to the general requirement, but vague when identifying implementation criteria. To ensure implementation, the following issues have been identified and resolved in advance so the implementation process will not be stopped to work on unresolved issues.

4.2.1 What are appropriate configurations for PCMs at the step off pad that allow personnel to use the PCM for CA egress?

Standards must be defined to allow evaluation of step off pad configurations to ensure the PCM is not used inappropriately.

Resolution: Appropriately designed egress points from contamination areas have common features. If the following configuration criteria are met, no restrictions should be placed on the movement of personnel from the step off pad to a PCM:

- the step off pad has survey instruments available

- the PCM is readily accessible without the necessity for opening doors, brushing walls, or other ancillary contact, the PCM is on the boundary between the Radiological Buffer Area and the uncontrolled area and, 
- the PCM is configured to see the total contamination levels established in HSRCM Table 2-2.

4.2.2 What defines "immediately", relative to when an exit survey is required?

This needs to be defined because the criteria is for an immediate survey after exiting the step off pad. Without definition, we risk multiple interpretations that will delay or hamper effective implementation.

Resolution: Immediate, relative to this issue, is access to the PCM without crossing an area that does not require an exit survey and is generally close, such as in the same room. Any step off pad meeting the criteria of 4.2.1 above would allow the person to exit the step off pad and progress to the PCM for a whole body survey. Work, loitering, otherwise spending time in the RBA beyond waiting for access to the PCM is not authorized. Movement from the step off pad to the PCM must be immediate.

4.2.3 What defines adjacent, relative to RBA survey after performing CA exit survey?

The criteria for adjacent need to be identified to define when an RBA exit survey need not be performed for persons exiting from a contamination area.

Resolution: The criteria noted in 4.2.1 and 4.2.2 above should be applied.

\subsubsection{Is specific training required?}

HSRCM 551.2 requires that personnel be trained on the instruments they use.

Resolution: Radiation Worker I and Radiation Worker II, along with the requalification classes, train personnel on the use of PCM-1Bs. Facility specific self survey (course number 350855 ) address portable instruments.

4.2.5 What survey must be done at the step off pad to allow access to PCM?

Clear standards for determining what is an appropriate survey are needed to ensure that the area between the step off pad and the PCM will not become contaminated. 
Resolution: For areas requiring an alpha and a beta-gamma survey, a whole body alpha survey will be required at the step off pad.

Assuming an operational PCM, the beta-gamma survey will be performed as follows:

[1] Frisk the hands before picking up the probe.

[2] Perform the frisk in the following order:

(a) Survey face (pause at mouth and nose for approximately 5 seconds)

(b) Shoe tops and bottoms (pause at sole and heel)

[3] Return the probe to its holder and leave the area. The probe should be placed on the side or face up to allow the next person to monitor their hands before handling the probe.

[4] Immediately exit the RBA through the PCM.

4.2.6 Are there any limitations on the practice, as related to self survey with portable instruments?

Self survey, using portable instruments, is currently authorized with limitations. IF the use of a PCM is to be considered a form of self survey, any limitations associated with the practice must be identified.

Resolution: Self survey is authorized per WHC-CM-4-14, Section 3.11. This procedure limits the use of self survey to work not involving respirators, or any other application of protective clothing beyond a single pair. Because there is no skill level involved in the use of a PCM, any limitations based on the skill of the person using the instrument are invalid. Because of this, no restrictions on the use of a PCM for self survey will be applied.

The current application of the PCM-1B still requires a supplemental hand frisk survey, and therefore, the limitations associated with self survey still apply. 


\subsubsection{Is the use of the PCM mandatory?}

Current practice has no requirement to use the PCM, except as noted on the RWP. There needs to be general criteria, communicated to all concerned as to whether a PCM is required to be used or not. This is not the type of practice that can be implemented piecemeal.

Resolution: A review of the criteria recommending the use of automated survey makes it clear that, when available, automated survey devices should be used. As a result, the policy on PCM usage established by this document will include the criteria that a PCM must be used, when available. Alternative survey methods may be used in conjunction with the PCM, but not in lieu of the PCM.

\subsection{IMPLEMENTATION}

\subsection{Communication}

This change must be clearly communicated to personnel. The primary mechanism for this will be required reading, safety meetings, all hands meetings, and other informal mechanisms used by the facilities to provide information to employees. A.ttachment 1 is a data sheet that will be circulated for the purpose of communicating this position.

A key item to be communicated is the somewhat subtle shift in criteria for PCM usage. The use of a PCM, when available, is not a mandatory requirement from the Radiological Control Manual or 10CFR835, it is a best management practice. Implementation must stress that this is a facility requirement, instituted by the facility, not a radiological controls requirement, driven external to the facility.

\subsection{Required Actions}

Tank Farm Self Survey Training must be modified. It must be noted that modifying the training will not invalidate training previously received, the employee communication process in section 4.1 will be the primary mechanism for communicating the change to our current work force.

ECD: 2 weeks from release of this document.

Survey instructions in accordance with HSRCM 338.8 must be prepared, approved and distributed. A sample copy is attached as Attachment 2, Sample Self Survey Instructions.

ECD: 2 weeks from release of this document. 


\subsection{REFERENCES}

1. HSRCM-1, Hanford Site Radiological Control Manual, Revision 2, dated December, 1994.

2. WHC-CM-4-14, Applied Radiological Controls, Section 3.11, Self Survey Implementation.

3. Internal Memo, May 19, 1992, R. E. Heineman to K. R. Jordan, 330000-92-028, Manual Surveys with Portal Monitor Surveys.

4. DSI, September 23, 1988, J. P. Gonsky to Rad. Eng. Staff, Technical Basis for Personnel Release using the PCM-1. 
General Hand-Held Instrument Requirements:

1. Verify that the instrument is in service, set to the $x 1$ scale, ensure beta/gamma background is <150 cpm and alpha background is $<3 \mathrm{cpm}$, and ensure the audio output can be heard.

2. Always survey hands before handling the probe.

3. Hold probe within $6 \mathrm{~mm}$ ( $1 / 4 \mathrm{inch})$ from surface being surveyed for beta/gamma or alpha contamination.

4. Move probe slowly over surface, approximately 2 inches per second.

5. IF the beta/gamma count rate increases $O R$ an alpha count occurs during frisking, pause for at least 5 seconds over the suspected area, THEN scan approximately $13 \mathrm{~cm}(5 \mathrm{in}$.) of the previous path at a reduced rate. If the increased counts persist, or if the instrument alarms, remsin in the area and notify Radiological Control personnel at

If the PCM-IB is operational then follow steps below:

1. Perform a whole body alpha survey, per general instructions if alpha survey required.

2. Perform beta-gamma survey as follows:

a. Survey face (pause at mouth and nose) for approximately 5 seconds.

b. Survey shoe tops and bottoms, pause at sole and heel.

c. Return the probe to its holder.

3. Proceed immediately through the RBA to the PCM-1B.

4. If the PCM-1B alarms, retry, if the PCM alarms for a second time remain in the area and contact Radiological Control personnel.

5. Personnel who have cleared the PCM and remain in the RBA must re-survey through the PCM-1B or perform a hand and foot survey prior to their exit.

If the PCM-IB in NOT operational, perform a whole body beta-gamma survey as shown below:

1. Perform survey as follows:

a. Frisk hands before handling the probe.

b. Perform the frisk in the following order:

(1) Head (pause at mouth and nose for approximately 5 seconds).

(2) Neck and shoulders

(3) Arms (pause at each elbow)

(4) Chest and abdomen

(5) Back, hips and seat of pants

(6) Legs (pause at each knee)

(7) Shoe Tops

(8) Shoe bottoms (pause at sole and heel)

(9) Personal and supplemental dosimetry.

2. Exit RBA immediately; if the RBA is not exited immediately, a hand and foot survey or PCM-1B survey must be performed at the RBA Boundary.

3. The whole body frisk should take at least two to three minutes. 


\section{Attachment 1: Presentation Media}

1. What is the purpose of a survey at a step off pad?

Personnel receive a whole body survey upon exit from a contamination area. Currently at Tank Farms this is done in one of two ways, an HPT performs a survey or personnel perform survey. This survey is performed to ensure the total contamination on a person exiting a contamination area at Tank Farms receives is not contaminated to greater than $5000 \mathrm{dpm} / 100 \mathrm{~cm}^{2}$ beta-gamma or $500 \mathrm{dpm} / 100 \mathrm{~cm}^{2}$ alpha.

2. Hlow will using a PCM change this?

Currently exit surveys are performed using hand held instrumentation. Where an alpha survey is required, there will be no change, an alpha survey will be performed at the step off pad, as is current practice. Beta-gamma surveys will be performed using the PCM1B. This is consistent with the methodology used at the 222-S Laboratory: a hand, foot, and facial survey will be performed at the step off pad, and then the worker will proceed directly to the PCM for a whole body release survey.

3. Am I at a greater risk?

No. Westinghouse Hanford, along with the majority of the nuclear industry has determined that the PCM is a better personnel survey device than hand held probes. The worker is at a reduced risk of undetected contamination where the PCM is used. Even though beta-gamma surveys are routinely performed prior to using the PCM, approximately $50 \%$ of skin and clothing contamination events are detected by automated counting systems, even though the individuals had, in most cases, undergone a portable irstrument survey.

4. Do I need to be self survey qualified to do this?

Yes. To survey off of the step off pad individuals must perform a survey of their hands, feet, and face. To perform this survey, individuals must be qualified to self survey. This training is currently available through Tank Farms Radiological Control, and in the future will be available during radiation worker training.

5. What if I want to self survey or have an HPT perform a survey.

The typical hand held beta-gamma survey meter meets the minimum standards for release and will continue to be authorized for use. It is the policy of Tank Farms that no individual will be required to perform a self survey. However, HPT resources are limited and while every effort will be made to have timely step off pad surveys, there will be some inherent delays in getting personnel off of step of pads. Every effort will be used to minimize this impact. Additionally, even if an HPT or self survey is performed, if a PCM is available at the RBA boundary, it must be used. 